\title{
Vocabulary Gender Patterns in EFL Compositions: a Cross Sectional and Longitudinal Study
}

\author{
Julieta Ojeda Alba y \\ Rosa María JimÉnez CataláN \\ Universidad de La Rioja
}

Received: 15 October 2008 / Accepted: 1 February 2009

ISSN: $1697-7467$

\begin{abstract}
The correlation between the level of lexical competence of an individual and his/her academic success has long been established, hence the importance of selecting the vocabulary input presented to language learners. The sex/gender variable may affect the way a learner acquires new words. With an eye on these factors the present paper analyses the vocabulary production of a sample of 204 EFL learners (102 males and 102 females) when writing school compositions at two stages of their learning process, $4^{\text {th }}$ year of primary school and $1^{\text {st }}$ year of ESO. The data obtained, we believe, may help designing classroom materials.
\end{abstract}

Key words: vocabulary, gender, longitudinal study.

Patrones de género en el vocabulario en redacciones en inglés como lengua extranjera: un estudio longitudinal transversal

RESUMEN: La correlación entre la competencia léxica de un individuo y su aprovechamiento académico se ha establecido hace tiempo, de ahí la importancia que tiene la selección del léxico que se presenta a los aprendices de una lengua; por otro lado, el factor sexo/ género es una variable que puede afectar el aprendizaje de una segunda lengua. Teniendo en cuenta estos aspectos, este trabajo analiza la producción léxica de 204 estudiantes (102 niños y 102 niñas) en dos fases de su aprendizaje, $4^{\circ}$ de primaria $1^{\circ}$ de la ESO. Consideramos que los datos obtenidos pueden ayudar al diseño de materials educativos.

Palabras clave: vocabulario, genero, estudio longitudinal.

\section{InTRODUCTION}

Although the role of vocabulary was disparaged for years in traditional second language teaching, it would now be superfluous to elaborate upon its role in the achievement of the slightest degree of linguistic proficiency (see, e.g., Carter, 1987; Meara, 1980; Meara, 1987; Nation, 1990; Richards, 1976; Schmitt \& McCarthy, 1997; Singleton, 1999; Wilkins, 1972). Moreover, one hypothesis which has gained almost universal acceptance in vocabulary research is the existence of a correlation between the level of lexical competence of an individual and 
his/her academic success (see, e.g., Alderson, 2000; Engber, 1995; Laufer \& Nation, 1995; Marzano, 2007; Morris \& Cobb, 2004). This awareness of the essential role of vocabulary expertise as a predictor of academic achievement has lead to studies which aim at determining the specific characteristics of the lexis in a given discourse: among other aspects the width and depth of word knowledge has been appraised (see, e.g., Hirsch \& Nation, 1992; Laufer \& Goldstein, 2004; Morris \& Cobb, 2004; Goulden \& Nation, 1990).

All these scholarly findings reached beyond the academic world when entrepreneurs and the man in the street became aware that vocabulary skills can contribute to social and financial success as well. The notion of the advantages of acquiring lexical richness is now deeply embedded in our first world countries, and an ever increasing number of pragmatically oriented ventures produce floods of advertising in an effort to sell their merchandise: books, courses, and multimedia teaching material allure the potential purchaser by promising a substantial enhancement of social status -a benefit to be obtainable by means of improving one's vocabulary (see, e. g., Harrington, 2000; Ickowicz, 1994; Miller \& Todd-Mancillas, 1998; Waitley, 2006). The promoter of one of those "how to be successful" commodities (in this case a set of CDs) introduces her product by asking the question, "What does vocabulary have to do with success?" and then to immediately respond herself with "Well, in a single word everything." (http:// www.executivevocabulary.com/). Another company also claims that a large vocabulary is the panacea for social success, and asks the audience: "Did you know that a powerful vocabulary is one of the most crucial keys to success in life?" and once again what they promise the prospective consumer is money and rapid success (http://www.bestshareware.net/download/ ultimate-vocabulary-success).

The benefits of acquiring greater vocabulary skills, in native as well as in foreign languages, obviously affect both sexes. Nevertheless, the two sexes do not seem to make the same selection of words, though in accord with Judith Butler's idea of performativity (1990: 24-25), we believe that gender displays do not necessarily correlate with biological sex, since individuals may enact a chosen gender rather than respond to physical characteristics.

The study of the complex interplay between gender-related issues and language is not new either, and today it is nearly a banality to argue its existence. Jespersen, already in 1922 , called attention to the differences between male and female language in the Antilles, and collected much of the pre-existing research on the language of women at the time; to be sure, the flourishing of these studies is relatively recent, but it has been ensconced in the collective consciousness for centuries. A fine source of early examples is found in the 1996 edition of Jennifer Coates' gender-related research book, Women, Men, and Language. Here the author asks a rhetorical question: "Do women and men talk differently?" to immediately demonstrate the stylistic function of her query by following it with a series of quotations from folklore, literature, and other such sources from as far back as the Middle Ages: all meant to illustrate that women and men do speak differently.

However, there exists some disparity of opinion. For instance, some scholars such as Weatherall (2002) don't see noteworthy differences between the language of the sexes; while others such as Mulac et al. (2001) report a good number of them. In spite of such conflicting opinions, there is wide consensus that each sex has its own idiosyncrasies in speech. More standardised tools and larger samples and corpora would greatly help, but are difficult to obtain and apply: we agree with Newman et al. who contend that one contributing aspect of 
the present confusion is "...the lack of a commonly accepted metric of analysis among empirical studies of language" (2008: 212). For our study, fortunately, we have been able to work with a sample of 204 participants and a total of 408 tests: the behaviour patterns that can be revealed from a corpus this size should not be underestimated.

Gender issues in association with language began to engage the interest of the academic world in a more persistent and methodical manner approximately three decades ago (see, e.g., Bodine, 1975; Key, 1975; Lakoff, 1975), and continued through the nineties when the interest crystallized in a number of seminal publications (see, e.g., Cameron, 1995 \& 1996; Coates, 1996; Kotthof \& Wodak, 1998; Tannen, 1990). Also, around the nineties a robust strand of research focusing on language and gender issues in SLA emerged and is still growing strong. In 2000 Jane Sunderland surveyed the situation in the English-speaking world and, as David Block (2002: 49) observed, Aneta Pavlenko et al. extended the review to include other languages (2005). Lately, many of the concerns of SLA research seem to have focused on approaches in which the consideration of the social and personal identity of learners, has come to the forefront. Numerous scholars now focus their research on the interaction between gender, social/ ethnic identities, and so on (see, e.g., Bremer et al., 1996; Bucholtz et al., 1999; Litosseliti \& Sunderland, 2002; Norton, 2000; Pavlenko, 2005).

Sense of identity and awareness of the self are shaped by a number of personal and socio cultural variables which influence the way in which a given individual learns and speaks first and second languages. These approaches, however, seem somewhat more pertinent for the analysis of the acquisition and learning in second language contexts rather than in foreign language circumstances. Our sample is purely EFL, and possibly one of the few clear-cut variables is anatomical sex which, though we do not intend to enter into this debate, we believe is inherently intertwined with other aspects of identity. Thus, with an eye on the gender identity factor, this study analyses and compares the vocabulary in the written production of a group of EFL learners from both sexes in the context of primary and secondary education.

\section{Methodology}

\subsection{Objectives}

This paper is ascribed to a longitudinal project which, beginning in 2003, has analysed the vocabulary implemented by 283 primary school students in a number of tasks written in three consecutive school years (2003-2006), when the informants were in grades $4^{\text {th }}, 5^{\text {th }}$, and $6^{\text {th }}$. The same team of researchers is now carrying out a follow-up of the said project initiated in $2007^{1}$. The goal of this second stage is to investigate the vocabulary produced by that same sample in their first three years of secondary education.

Within the framework of this project, the objective of this study is to examine the vocabulary produced by a portion of this sample in a writing task at two different stages of their EFL learning process: the two cross-sectional slices chosen here are $4^{\text {th }}$ year of primary school and $1^{\text {st }}$ year of $\mathrm{ESO}^{2}$. We focus on the types and tokens pertaining to three centres of interest

1. We would like to acknowledge here the financial support of FEDER and MEC through grant HUM 200609775-C02-02.

2. Within the Spanish education system ESO is the acronym for "Obligatory Secondary Education". 
selected because of their importance in gender and language research: colours, body parts, and clothing items. Our chief objective is to compare the vocabulary usage of both males and females in both slices to ascertain whether the sex variable affects their performance and, if so, in which ways. In addition, we give some preliminary interpretation of the results that may be applied to EFL instruction procedures, and to the designing of educational materials, namely the selection of classroom vocabulary input. All this is summarised in the following research questions:

1. What number of types and tokens does a sample of $4^{\text {th }}$ year primary school students produce on the whole and on three selected lexical fields when writing school compositions meant to encourage the writer to self definition?

2. In which way do figures alter in the same task produced by the same sample three years later?

3. Are meaningful differences found when comparing the male and female production?

\subsection{Informants, instruments, and procedures}

As observed above, in the present study 204 informants (102 females and 102 males) participate. This figure of eligible participants is the result of balancing the gender distribution, which made the random exclusion of a number of males necessary. Additionally, all the informants who had not completed either the first or the second written tasks were also necessarily left out. The task analysed in this case is a letter composition to an imaginary host family from Oxford, England. The subjects received the following written guidelines together with an explanation in Spanish:

Imagine you are going to live for a month with an English family (the Edwards), in Oxford. There are four members in the family: Mr. and Mrs. Edwards, and the children Peter and Helen. Write a letter to them in English in which you should introduce yourself, and tell them about your town, your school, your hobbies, and any other thing of interest that you would like to add.

The total number of compositions in this corpus reaches the figure of 408: two by each participant. Consequently, each student completes exactly the same task twice, after an interval of three years. The first set of compositions was written when participants had attended an average of 340 hours EFL tuition, (average age \pm 10 ); the second when they had received an average of 670 hours tuition, (average age \pm 13 ). Once the compositions were deciphered and weeded out of Spanish words, they were electronically encoded, then all the words related to the targeted lexical fields were isolated and analysed.

\section{RESUlts AND DISCUSION}

\subsection{Global results}

From the analysis of our corpus, which for clarification purpose is subdivided into four sub-corpora by sex and course criteria, emerges a pattern consistent in some ways with previous findings achieved by members of the GLAUR research group (see, e.g., Agustín \& 
Jiménez, 2007; Jiménez, 2003; Jiménez \& Ojeda, 2008; Ojeda \& Jiménez, 2007), while it also reveals new and unexpected data. Table 1 shows the global number of types and tokens produced by each of the sexes in the two cross-sectional slices here analysed. On the whole, females' production exceeds that of males.

A remarkable feature which affects both sexes is the meagre increase of terms that takes place between slices. Moreover, as seen in table 1, the females' total type implementation increase is even lower than the males'. When focusing on types related to our three centres of interest there is, in fact, an overall diminution between slices rather than an increase: females produce three types fewer and males eight types fewer in the second slice than in the first (tables $2 \& 3$ ), though this result is chiefly due to the dissimilarities in just one lexical field, that of clothes.

Table 1. Global Production of Types and Tokens.

\begin{tabular}{lllll}
\hline School Year & Types & & Tokens & \\
& Males & Females & Males & Females \\
$4^{\text {o }}$ Primary & 1.707 & 1.998 & 9.117 & 11.620 \\
$1^{\text {st }}$ ESO & 2103 & 2200 & 13.817 & 18.225 \\
\hline
\end{tabular}

These data are particularly surprising when we consider that our informants grow out of childhood and into early adolescence precisely during the three-year span elapsed between the administration of both tests; and evolutionary psychologists contend that early adolescents show a high interest in topics related to self-image, and the shaping of personality (see, e.g., Elkind, 1967; Inhelder \& Piaget, 1958; Mitchel, 1998; Santrock, 2001). The discussion of body parts, clothes, and their colours fall into these categories, and thus were a priori expected to be widely implemented.

In spite of their slower increase rate between slices females prove to be more articulate than males also in the three centres of interest. They demonstrate that by producing a higher global number of both types and tokens in both slices (tables $2 \& 3$ ). In addition, the terms implemented are more widely distributed among the participants in the female than in the male corpora (table 4). In the first cross-sectional slice, 42 out of 102 males use vocabulary connected to at least one of our three lexical fields; while among the females we find as many as 63 informants.

Three years later, when the second test is conducted, the breach between the sexes widens even further. Twelve more subjects, (5.88 \% higher participation than in the first slice) implement related vocabulary. The distribution between the sexes is as follows: nine more females, $8.82 \%$ higher participation; and three more males, $2.94 \%$ higher participation. 
Table 2. Types \& Tokens $4^{\text {th }}$ Primary School: Colours, Body-parts, and Clothes.

\begin{tabular}{llclc}
\hline Lexical Field & \multicolumn{2}{c}{ Males } & \multicolumn{2}{c}{ Females } \\
& Types & Tokens & Types & Tokens \\
Colours & 11 & 72 & 13 & 232 \\
Body parts & 9 & 27 & 5 & 90 \\
Clothes & 18 & 60 & 22 & 80 \\
Total & 38 & 162 & 39 & 402 \\
\hline
\end{tabular}

Table 3. Types \& Tokens $1^{\circ}$ Year ESO: Colours, Body-parts, and Clothes.

\begin{tabular}{lllll}
\hline Field & \multicolumn{2}{c}{ Males } & \multicolumn{2}{c}{ Females } \\
& Types & Tokens & Types & Tokens \\
Colours & 11 & 82 & 15 & 177 \\
Body terms & 9 & 52 & 9 & 82 \\
Clothes & 10 & 19 & 13 & 33 \\
Total & 30 & 153 & 36 & 292 \\
\hline
\end{tabular}

Table 4. Participants' Implementation of Colours, Body-parts, and Clothes.

\begin{tabular}{lllllll}
\hline \multirow{2}{*}{ Year } & \multicolumn{2}{c}{ Raw 204 subjects } & \multicolumn{2}{c}{ Males 102 subjects } & \multicolumn{2}{c}{ Females 102 subjects } \\
& Subjects & Percent. & Subjects & Percent. & Subjects & Percent. \\
$4^{\text {th }}$ Prim & 105 & $51.47 \%$ & 42 & $41.17 \%$ & 63 & $61.76 \%$ \\
$1^{\text {st }}$ ESO & 117 & $57.35 \%$ & 45 & $44.11 \%$ & 72 & $70.58 \%$ \\
\hline
\end{tabular}

In the following paragraphs we examine in some detail the production of each one of these three centres of interest separately.

\subsection{Colour-naming}

Scholarly studies have claimed that colour discrimination is not yet fully activated in very young children, (see, e.g., Bornstein, 1985; Cruse, 1977; Johnson, 1977). Bornstein observed that "very young children's colour naming develops slowly and anomalously" (1985:388). Sociolinguists also argued that, later in life, when both sexes achieve higher skills in colour 
naming, females' discrimination is more accurate than males' (see, e.g., Frank, 1990; Rich, 1977; Swaringen et al., 1978). However, Yonglin Yang aptly observed that previous research had mostly analysed adult native English speakers (2001: 239). The conditions Yang highlighted are still unaltered: few studies have aimed at determining the correlation between sex and colour-naming in learners whose native language is other than English (see, e.g., Thomas et al., 1978; Yang, 2001), and we have not found any studies conducted with primary school EFL learners whose native language is Spanish. The present paper aims at filling that existing gap to some extent.

In table 5 we can see the numbers and percentages of participants who implement colour terms in both slices: 51 males use at least one colour in at least one of the two cross-sectional slices; while as many as 79 females do the same. In the same key, only five males produce colour terms in both corpora; while among the females there are 29 subjects.

\section{Table 5. Informants who implement Colour Terms.}

\begin{tabular}{lllll}
\hline Year & Participants & \multicolumn{3}{l}{ Percentages } \\
& Males & Females & Males & Females \\
Either $2004 / 2007$ & 51 & 79 & $50 \%$ & $77.45 \%$ \\
2004 & 28 & 52 & $27.45 \%$ & $50.98 \%$ \\
2007 & 28 & 57 & $27.45 \%$ & $55.88 \%$ \\
$2004 \& 2007$ & 5 & 29 & $4.90 \%$ & $28.43 \%$ \\
\hline
\end{tabular}

In this lexical field the two male corpora show the same number of types in the two cross-sectional slices; while the females produce two more types in the second slice than in the first (tables $6 \&$ 7). Comparing both sexes, the female sample yields a slightly higher production in both cross-sectional slices: two more types in the first one, and four more in the second. In all four sub-corpus the superordinate "colour" achieves an advantageous position in the ranking.

Although type number differences in favour of the female corpus may be quantitatively unimportant, they are qualitatively suggestive. For instance, in the first slice, the two additional types produced by the female sample (but not by the male sample) are "pink" and "blond". The former is a colour traditionally associated to the female domain which in our Western culture, according to Calthas-Coulthard and Van Leeuwen, "has (acquired) a definite, and further, association for what it is to be female." (2002: 101). The latter is a tinge of hair colour clearly connected to awareness of looks. In Mediterranean male imagery blond hair is also invested with eroticism when applied to women and, curiously, this type appears in the second cross-sectional slice male corpus, when the participants are entering their teens and are awakening to new physical demands.

In the second slice, females produce two new terms, "light" and "dark", which are not implemented by males in either of the two cross-sectional slices. These two terms serve to further qualify colours, revealing in females an incipient tendency towards a more sophisticated 
use of the language and a more accurate application of colour terms. This finding corroborates that of Nowaczyk who, in an experiment conducted with college students in 1982, found that females used more elaborated colour terms than males, as well as the results obtained by (Jiménez \& Ojeda, 2008).

As for the amount of tokens, there is a quantitatively remarkable disparity between the sexes: in the first cross-sectional slice females use over three times as many colour tokens as males; and in the second over twice as many. Also, while among the females the number of tokens decreases substantially between slices, among the males the alteration is in the opposite direction.

Table 6. Colours First Cross-sectional Slice.

\begin{tabular}{llll}
\hline & Males & & Females \\
Types & Tokens & Types & Tokens \\
Colour & 15 & Brown & 79 \\
Black & 12 & Blue & 30 \\
Brown & 9 & Green & 18 \\
Blue & 7 & Orange & 18 \\
Green & 7 & Black & 16 \\
Red & 7 & Red & 15 \\
Yellow & 6 & Colour & 14 \\
Orange & 5 & White & 11 \\
White & 2 & Yellow & 9 \\
Grey & 1 & Grey & 8 \\
Purple & 1 & Purple & 8 \\
& & Blond & 3 \\
Total 11 & & Pink & 3 \\
\hline
\end{tabular}


Table 7. Second Cross-sectional Slice.

\begin{tabular}{llll}
\hline & Males & & Females \\
Types & Tokens & Types & Tokens \\
Brown & 24 & Brown & 53 \\
Blue & 11 & Colour & 22 \\
Colour & 10 & Black & 18 \\
Black & 9 & Blue & 18 \\
Blond & 7 & Green & 14 \\
White & 7 & White & 11 \\
Red & 5 & Blond & 6 \\
Green & 4 & Pink & 8 \\
Orange & 2 & Dark & 6 \\
Yellow & 2 & Red & 6 \\
Pink & 1 & Orange & 5 \\
& & Yellow & 4 \\
& & Purple & 3 \\
& & Grey & 2 \\
Total 11 & & Light & 1 \\
\hline
\end{tabular}

\subsection{Body-part naming}

The lexical field of body parts is one of the areas in which Jespersen found that the speech of women and men differed most. Our results are in full agreement with him, and with the view of a number of scholars (see, e.g., Alicke \& Klotz, 1986; Neumark- Sztainer, 2005; Stenström et al., 2002; Tondl, 1994). Stenström et al. observe that "only the girls have lengthy and detailed conversations about how they work on their body to look nice" (2002: 43); and referring to American girls Brumberg contends that they are obsessed with their bodies (1997).

A remarkable trend is the fact that most of the body-part tokens used are occurrences of only two types: "eyes" and "hair", in the first slice these terms represent $51.72 \%$ of the male production and $80.64 \%$ of the females' contribution. In the second slice they represent $69.23 \%$ of the male production and $79.51 \%$ of the females' contribution. Moreover, as can be observed in tables 8 and 9, they alone are responsible for all but two of the additional tokens in the second male cross-sectional slice.

Our informants" focus on the "eyes" is consistent with the assessment of a number of psychologists. The social meaning of "eye contact" and "gaze" has frequently been studied 
(see, e.g., Bordo, 1993; Farroni \& Johnson, 2006; Johnson \& Farroni, 2007). "Hair" enjoys an analogous status: Galasinski calls attention to the significance of hair for men as well as for women (2004: 42-43); Catherine Derry believes that "A girl's hair is considered to be second in importance to the dress" (2004: 48), and Robert Bartlett observes that "styles of head and facial hair in our own society convey meanings about status, attitude and role" (1994: 43).

Both "eyes" and "hair" are commonly believed to play a role in essential human activities such as that of courtship. This alleged function is reflected even in Internet where websites highlight the importance of both when trying to find a mate. One of them gives teenagers the "Top Flirting Tips for Teenagers" thus:

Make eye contact from across the room and quickly look away. Make eye contact again, hold their gaze for a few seconds and smile. Then look away again."

Playing with hair (flipping it, twirling it, and so on) is a common flirty body language tactic among women.

(http://teens.lovetoknow.com/Flirting_Tips_for_Teenagers)

The significance of "eyes" in Western lore is reflected in the well-known proverb, "Eyes are the mirrors of the soul" and, although "eye contact" may trigger opposite responses in some cultures, in mainstream western society, staring and gazing are well known strategies to engage in human relationships. "Hair" can be said to have multiple functions, apart from its significance as a human beign's natural ornament, its symbolic power is reflected in literature: for instance in Pre-Raphaelites" representations or in the Grimm brothers' fairy tale "Rapunzel". In the latter hair becomes a tool by means of which salvation is attained. The strong roots of these two body parts in western lore may explain their comparatively high frequency in our corpus.

Altogether, females seem more interested in this centre of interest than males, and they prove it by using more tokens in both slices, and by a higher proportion of subjects implementing them. In the first cross-sectional slice $14.70 \%$ of the males and $35.29 \%$ of the females produce at least one type related to this lexical field; and similar proportions are maintained in the second slice, where $19.60 \%$ of the males and $38.23 \%$ of the females implement this centre of interest. Indeed, males produce four more types than females in the first crosssectional slice, but each one of them happens to be a hapaxlegomena and, therefore, the difference is quantitatively inconsequential. Curiously, and perhaps coincidentally, some of these additional terms, for example "arm" or "toe", are associated to sports.

The number of types and tokens implemented by each of the sexes alters from the first to the second slice in different ways. Males produce the same number of types in both slices, while the number of tokens is almost twice as large in the second: the effect is a considerably higher lexical reiteration in the second slice. On the contrary, females produce four more types and eight tokens fewer in the second slice, thus achieving higher lexical richness in this field. Some of these findings do not fulfil previous estimations: neither the total number of types, nor the increase between both cross-sectional slices are as substantial as they were expected to be. We recall once again the fact that the interval between both corpora is precisely when early adolescents are in the phase of their cognitive development in which their image is extremely important to them. If, indeed, the myth of the "Imaginary Audience" prevails at this age, as Elkind, \& Bowen believed (1979), a more extensive presence of their bodies and their looks would have been consistent. 
Table 8. First Cross- sectional Slice: Body Parts.

\begin{tabular}{lllc}
\hline \multicolumn{1}{c}{ Males } & & Females \\
Types & Tokens & Types & Tokens \\
Eyes & 11 & Hair & 40 \\
Nose & 5 & Eyes & 35 \\
Hair & 4 & Mouth & 7 \\
Mouth & 2 & Nose & 7 \\
Ears & 1 & Ears & 1 \\
Arms & 1 & & \\
Body & 1 & & \\
Face & 1 & & 90 \\
Toe & 1 & & \\
Total 9 & 27 & Total 5 & \\
\hline
\end{tabular}

Table 9. Second Cross- sectional Slice: Body Parts.

\begin{tabular}{lclc}
\hline & Males & & Females \\
Types & Tokens & Types & Tokens \\
Hair & 22 & Hair & 34 \\
Eyes & 17 & Eyes & 32 \\
Foot & 5 & Foot & 6 \\
Ear & 2 & Ear & 4 \\
Skin & 2 & Nose & 2 \\
Body & 1 & Beard & 1 \\
Face & 1 & Body & 1 \\
Hand & 1 & Freckles & 1 \\
Nose & 1 & Leg & 1 \\
Total 9 & 52 & Total 9 & 82 \\
\hline
\end{tabular}




\subsection{Clothes naming}

Attire has always had a central social function in human communities; Dietmar Neufeld argues that the values of a certain society are often reproduced in dressing motifs, and he demonstrates how this notion is operative in the mind of the author/ authors of the Bible (2001). The symbolic significance of clothes is a widely shared belief: scholars agree that, in a direct or indirect manner, what a person wears relates to his/her personal and social identity (see, e.g., Burman \& Turbin, 2003; Flügel, 1930; Holman, 1980; Elliott \& Wattanasuwan, 1998). Elliott, for instance, believes that individuals serve themselves of many products and brands to shape and preserve their own identities (1999).

Most particularly, teenagers' interest in clothing is generally acknowledged; Smith et al. observed in a document by the the Smithsonian Institution, Office of Elementary and Secondary Education: "To the chagrin of both parents and teachers, clothing and personal appearance are subjects that almost never fail to win the attention of young people." (1990: 6). Clothes often aim at expressing what youngsters believe to be their own identity, and they attempt to imbue the garments they wear with symbolic properties (see, e.g., Davis, 1992; Gilbert \& Taylor, 1991; Leblanc, 1999).

Again, in this area, the number of terms implemented by both sexes seems comparatively low, particularly if we consider that the task allotted is intended to be the participants' letter of introduction. Moreover, we should also keep in mind that within this centre of interest are included accessories such as "glasses" or "piercing", and even the container where clothes are kept, "wardrobe".

Clothes and the choosing and buying of garments is considered a gender-related activity which attracts teens and in particular female teens (see. e.g., Elliott, 1993; Freedman, 1984; Solomon, 1996). Here, again, the females' production is larger than the males', and also a larger number of females implement it. In the first slice, 17 males produce 60 tokens $(16.66$ $\%$ of this sub-corpus production); while 27 females produce 80 tokens $(26.47 \%)$. In the second slice 11 different males implement 19 tokens (10.78\%); while 14 females produce 33 tokens $(13.72 \%)$.

In addition, there is once again in both sexes a decrease, rather than an increase, of type and token production from the first to the second slice. In the case of types the number is reduced almost to a half: decreasing from 18 types to 10 in the male corpus, and from 22 to 13 in the female corpus. In the case of tokens the diminution is even more sizeable, decreasing to a third among the males, and almost to a fourth among the females. 
Table 10. First Cross - sectional Slice: Clothes Naming.

\begin{tabular}{|c|c|c|c|}
\hline \multicolumn{2}{|c|}{ Males } & \multicolumn{2}{|c|}{ Females } \\
\hline Types & Tokens & Types & Tokens \\
\hline Wardrobe & 9 & Trousers & 11 \\
\hline Trousers & 7 & Glasses & 10 \\
\hline T-shirt & 7 & T-shirt & 8 \\
\hline Shoes & 6 & Clothes & 7 \\
\hline Jumper & 5 & Bag & 5 \\
\hline Shirt & 4 & Jacket & 5 \\
\hline Socks & 4 & Jumper & 5 \\
\hline Skirt & 2 & Wardrobe & 5 \\
\hline Boots & 2 & Jeans & 3 \\
\hline Clothes & 2 & Shirt & 3 \\
\hline Coat & 2 & Skirt & 3 \\
\hline Glasses & 2 & Coat & 2 \\
\hline Hat & 2 & Fashion & 2 \\
\hline Trainers & 2 & Shoes & 2 \\
\hline Bags & 1 & Trainers & 2 \\
\hline Jeans & 1 & Boots & 1 \\
\hline Shorts & 1 & Dress & 1 \\
\hline \multirow[t]{5}{*}{ Umbrella } & 1 & Hat & 1 \\
\hline & & Goggles & 1 \\
\hline & & Schoolbag & 1 \\
\hline & & Short & 1 \\
\hline & & Track-suit & 1 \\
\hline Total 18 & 60 & Total 22 & 80 \\
\hline
\end{tabular}


Table 11 Second Cross- sectional Slice: Clothes Naming.

\begin{tabular}{llll}
\hline & Males & & Females \\
Types & Tokens & Types & Tokens \\
Clothes & 4 & Clothes & 9 \\
Jeans & 3 & Trousers & 5 \\
Trainers & 3 & Uniform & 3 \\
Glasses & 2 & Boots & 2 \\
Jumper & 2 & Dress & 2 \\
Hat & 1 & Jacket & 2 \\
Helmet & 1 & Jeans & 2 \\
Piercing & 1 & Jumper & 2 \\
Shirt & 1 & T-shirt & 2 \\
Sweatshirt & 1 & Shirt & 1 \\
& & Shoes & 1 \\
Total 10 & & Skirt & 1 \\
\hline
\end{tabular}

\section{Conclusions}

The findings reported here reveal that our female informants globally generate a larger production than the males, at least when writing a letter composition school task. Focusing on the three selected centres of interest the scenario remains rather similar. When each lexical field is separately examined we detect one exception: males produce 4 more types than females in the body-part first cross-sectional slice; this exception, however, does not contradict our initial claim of female supremacy, it rather appears as a chance occurrence after we consider two aspects: first, every single type that males implement and females don't is a hapaxlegomena; second, in that same section males produce 27 tokens, while females produce 90.

More consequential to establish the impact of lexical implementation in these areas seems the production distribution among the informants. The vocabulary output has been produced by a larger number of female participants in both sub-corpora: in the first slice female participation surpasses the males' by $20.59 \%$; while in the second slice females' participation exceeds males' by $26.47 \%$. 
One of the most suggestive findings is the general scantiness of the overall production of types related to our three centres, mainly if we recall that these fields comprise many terms included in the Brown Corpus 1000 word frequency list (Francis and Kucera, 1982: 132). The figures continue low in the second slice, though between the administration of both tests three years elapse, and the informants receive an average of 111 additional hours of EFL tuition per year. In the male corpus, though two fields have an equal number of types in both slices, the final count shows a reduction of eight types in the second. In the female corpus, though two fields increase in number of types and one decreases, the final count also shows a reduction of three types.

Summarising, the present paper has offered the following data:

1. The total number of types and tokens that a sample of $4^{\text {th }}$ year primary school students implement on the whole and on three specific lexical fields when writing a guided letter composition.

2. The total number of types and tokens produced by the same sample in the same test conducted three years later when the participants were attending $1^{\text {st }}$ year of ESO.

3. A comparison of the male and female production which confirms that in both crosssectional slices females produce a larger figure.

Can these findings be applied to the improvement of EFL teaching? We believe they can. Awareness of similarities and dissimilarities in the performances of each sex assists teachers in designing and selecting classroom materials. In this case it seems that for both sexes a more suitable lexical classroom input would be advantageous.

In foreign language instruction, for students who have no other sources of exposure, the vocabulary input received from text books and teacher classroom language correlates with their linguistic competence and performance. We believe that this is mostly so in Spain, where, due to the limited access to linguistic resources Spanish primary and secondary EFL students have, (as opposed the situation in areas such as northern European countries) the exposure to any L2 most learners have is restricted to classroom input. As a result, classroom materials largely determine their vocabulary competence.

A scrutiny of the course books used by our informants in both, the $4^{\text {th }}$ year of primary school and the $1^{\text {st }}$ year of ESO, discloses the restrictions imposed upon them by their English lexicon. Although a great deal of the vocabulary needed for a physical description may be described as core English, not much vocabulary pertaining to our three fields had been presented or reviewed by means of textbooks. This inclines us to speculate that one reason why the participants do not use as many terms as expected, is simply because they are unfamiliar with the required words.

No doubt the learners' self-perceptions of the world around them might have determined also their vocabulary choices, but their lexical reiteration suggests that the topics interest them more than the limited number of types indicates.

Nevertheless, this is a preliminary study, and suffers from a number of limitations. A variety of more specific tests should be given to learners in the future to assess aspects such as motivation, word availability, and the like, before arriving to any firm conclusions. For instance, had we passed an availability test to our sample, the assessment of whether the number of terms implemented reflect the informants' expertise or their preference for the topics could have been more accurately determined. In this respect, the above mentioned case of the term "wardrobe" is very telling: it seems clear that its relatively frequent presence in 
our corpus is not the result of the participants' concern about containers, but rather the consequence of its availability to them: in consequence, it is an example of the importance of the received classroom input when it comes to students' written production. Additional tests should have also been conducted to prove or disprove task effect. At any rate, we believe that cases like this must be studied in depth, for they may clarify what triggers vocabulary acquisition. At this point, however, the question remains, why should our informants implement the term "wardrobe" in preference to "T-shirt", "jeans", or "skirt?"

Another limitation in this paper is that we have applied only descriptive statistical analyses. In consequence, though our results are suggestive, in order to corroborate whether the findings obtained are significant or merely a chance occurrence further inferential statistics should be applied to the data.

Additionally, the influence of anatomical sex might be analysed. For instance, in the lexical field of colours, results like ours have provided stimulus to speculate whether there is a genetic foundation that explains this greater female dexterity in colour naming (Mollon, 1986; Rosch, 1975; Swaringen et al, 1978). We, however, tend to have a more cultural approach, and are inclined to believe that these results are mostly the consequence of a gendered-learned and culturally constructed behaviour.

\section{REFERENCES}

Agustín Llach P. and Jiménez Catalán, R. M. (2007). "Lexical reiteration in EFL young learners' essays: does it relate to the type of instruction?", in IJES, 7, 2: 85-103.

Alicke, M., Smith, R., and Klotz, M. (1986). "Judgements of physical attractiveness: The role of faces and bodies", in Personality and Social Psychology Bulletin, 12: 381-347.

Barlett, Robert. (1994). "Symbolic meanings of hair in the Middle Ages", in Transactions of the Royal Historical Society, Sixth Series, 4: 43-60.

Block, David. (2002). "Language and gender and SLA". in Quaderns de Filologia. Estudis Lingüistics. vol. VII: 49-73.

Bodine, Ann. (1975). "Sex differentiation in language", in B. Thorne and N. Henley, Language and Sex. Rowley, MA: Newbury House Publishers, 130-151.

Bordo, S. (1993). Unbearable Weight: Feminism, Western Culture and the Body. Berkeley: University of California Press.

Bornstein, M. H. (1985). "Colour-name versus shape-name learning in young children" in Y. Child Language, 12: 387-393.

Brumberg, J. J. (1997). The Body Project: An Intimate History of American Girls. New York: Random House.

Bucholtz, M., A. C. Liang and Sutton, L. A. (eds.)(1999). Reinventing Identities: The Gendered Self in Discourse. New York: Oxford University Press.

Burman, B. and Turbin, C. (eds.)(2003). Material Strategies: Dress and Gender in Historical Perspective. Oxford, U.K.: Blackwell Publishing.

Butler, J. (1990). Gender Trouble: Feminism and the Subversion of Identity. New York: Routledge.

Calthas-Coulthard, C. R. and Leeuwen, T.V. (2002). "Stunning, shimmering, iridescent", in Litosseliti and Sunderland (eds.), in Gender Identity and Discourse Analysis, 91-108.

Cameron, Deborah. (1995). "Rethinking language and gender studies: some issues for the 1990s", in S. Mills (ed.), Language and Gender Interdisciplinary Perspectives. London: Routledge, $31-44$. 
Cameron, Deborah. (1996). "The language gender interface: challenging co-optation", in Victoria Bergvall, J. Bing and A. Freed (eds.), Rethinking Language and Gender Research. London: Longman.

Carter, R. (1987). Vocabulary: Applied Linguistic Perspectives. London: Allen \& Wind.

Coates, J. (1986). Women, Men and Language: A Sociolinguistic Account of Gender Differences in Language. London \& New York: Longman.

Coates, J. (ed.) (1998). Language and Gender: A Reader. London: Routledge.

Cruse, D. A. (1977). "A note on the learning of colour names" in Y. Child Language 4: 305-311.

Davis, F. (1992). Fashion, Culture and Identity. Chicago: University of Chicago Press.

Derry, C. (2004). "'I'll never find a dress': dressing for the prom", in S. Weber and C. Mitchel (eds.), Not Just any Dress. New York: Peter Lang.

Elkind, D. (1967). Egocentrism in adolescence", Child Development, 38, 4: 1025-1034.

Elkind, D., and Bowen, R. (1979). "Imaginary audience behaviour in children and adolescents", Developmental Psychology, 15, 38-44.

Elliott, R. and Wattanasuwan, K. (1998). "Brands as symbolic resources for the construction of identity", in International Journal of Advertising, 17, 2: 131-145.

Elliott, R. (1993). "Gender and the psychological .meaning of brands", in J. A. Costa (ed.), Gender and Consumer Behaviour, vol. 2. Salt Lake City, UT: University of Utah Press, 156- 168.

Elliott, R. (1999). "Symbolic meaning and postmodern consumer culture", in D. Brownlie, M. Saren, R. Wensley, R. Whittington, R. (eds.), Rethinking Marketing: Towards Critical Marketing Accountings. London: Sage Publications, 111-125.

Engber, C. A. (1995). "The relationship of lexical proficiency to the quality of ESL compositions" in Journal of L2 Writing, 4, 2: 138-155.

Farroni, T., Menon, E., and Johnson, M.H. (2006). "Factors influencing newborns preference for faces with eye contact" in Journal of Experimental Child Psychology, 9: 298-308.

Flügel, J. C. (1976). The Psychology of Clothes. Brooklyn, N.Y. AMS Press.

Francis, W. N. and Kucera, H. (1982). Frequency Analysis of English Usage. Boston: Houghton Mifflin.

Frank, J. (1990). “Gender Differences in Color Naming”, in American Speech, vol. 65, 2: 114-126.

Freedman, R.J. (1984). "Reflections on beauty as it relates to health in adolescent females" in Women and Health, 9, 2/3: 29-45.

Galasinski, D. (2004). Men and the Language of Emotions. Houndmills \& New York: Palgrave McMillan.

Gilbert, P. and Taylor S. (1991). Fashioning the Feminine: Girls, Popular Culture and Schooling. Allen and Unwin, Sydney.

Goulden, R., Nation, P. and Read, J. (1990). "How large can a receptive vocabulary be?" in Applied Linguistics, 11: 341-363.

Harrington E. C. (2000). Verbal Advantage: 10 Easy Steps to a Powerful Vocabulary. New York: Random House.

Hirsch, D. and Nation, P. (1992). "What vocabulary size is needed to read unsimplified texts for pleasure?" in Reading in a Foreign Language, 8, 2: 689-696.

Holman, R. H. (1980). "Clothing as communication: an empirical investigation" in Advances in Consumer Research, 7: 272-377.

Ickowicz, C. (1994). Word Power: Vocabulary of Success. Teaneck, NJ: Dashir Inc.

Inhelder, B. and Piaget, J. (1958). The Growth of Logical Thinking. New York: Basic Book.

Jespersen, Otto. (1922). Language: Its Nature, Development, and Origin. London \& New York: George Allen \& Unwin. 
Jiménez Catalán, R M. (2003). “Sex differences in L2 vocabulary learning strategies”, in International Journal of Applied Linguistics, vol. 13, 1: 54-76.

Jiménez Catalán, R. M. and Ojeda Alba, J. (2008). "The English vocabulary of girls and boys: similarities or differences? Evidence from a corpus-based study" in K. Harrington, L. Litosseliti, H. Sauntson, and J. Sunderland (eds.), Language and Gender Research Methodology. London: Palgrave Macmillan.

Johnson, E. G. (1977)."The development of colour knowledge in preschool children" in Child Development, 48: 308-311.

Johnson, M.H., and Farroni, T. (2007). "The Neurodevelopmental origins of eye-gaze perception", in R. Flom, K. Lee and D. Muir (eds.), Gaze-Following: Its Development and Significance. Mahwah, N.J: Laurence Erlbaum Associates, 1-16.

Key, M. R. (1975). Male/Female Language. Metuchen: Scarecrow Press.

Kotthof, Helga and Ruth Wodak (eds.)(1998). Communicating Gender in Context. Amsterdam: John Benjamins.

Lakoff, R. (1975). Language and Woman's Place. New York: Harper \& Row.

Laufer, B and Nation, P. (1995). "Vocabulary size and use: lexical richness in L2 written production", in Applied Linguistics 16,3: 307-322.

Laufer, B. and Goldstein, Z. (2004). "Testing vocabulary knowledge: size, strength, and computer adaptiveness", in Language Learning 54: 469-523.

Leblanc, L. (1999). Pretty in Punk: Girls' Gender Resistance in a Boys'Subculture. New Brunswick, NJ: Rutgers University Press.

Litosseliti, L. and Sunderland, J. (2002). Gender Identity and Discourse Analysis. Amsterdam: John Benjamins.

Marzano, R. J. (2007). “The Role of Vocabulary Instruction in Improving Students' Academic Achievement", PowerPoint presentation: Mississippi Department of Education.

Meara, P. (1980). "Vocabulary acquisition: a neglected aspect of language learning" in Language Teaching and Linguistic Abstracts 13: 221-246.

Meara, P. (1987). "Vocabulary in a second language" in vol. 2 London: Scottish Centre for Information on Language Teaching and Research.

Miller, M. and Todd-Mancillas, W. R. (1998). Vocabulary of Success. Indianapolis, Indiana: Webster's New World.

Mitchell, J.J. (1998). The Natural Limitations of Youth: the Predispositions that Shape the Adolescent Character. Stamford, CT: Ablex Publishing.

Mollon, J. D. (1986). "Questions of sex and colour", in Nature 323,16: 578-579.

Morris, L. and Cobb, T. (2004). "Vocabulary profiles as predictors of the academic performance of teaching English as a second language trainees", in System 32, 1: 75-87. PDF.

Mulac, A., Bradac, J. J., and Gibbons, P. (2001). "Empirical support for the 'gender as culture' hypothesis: An intercultural analysis of male/female language differences", in Human Communication Research, 27: 121-152.

Nation, P. (1990). Teaching and Learning Vocabulary. Boston, MA: Heinle \& Heinle.

Neufeld, D. (2001). Body Decoration and Clothing in the Revelation of John. Pretoria: The International Context Group. University of South Africa.

Neumark-Sztainer, D. (2005). I'm, Like, So Fat!: Helping Your Teen Make Healthy Choices about Eating and Exercise in a Weight-obsessed World. New York: Guilford Publications, Inc.

Newman, M.L., Groom, C. J., Handelman, L.D., Pennebaker, J.W. (2008). "Gender Differences in Language Use: An Analysis of 14,000 Text Samples", in Discourse Processes: A Multidisciplinary Journal, 45, 3: 211-236. 
Norton, Bonny. (2000). Identity and Language Learning: Gender, Ethnicity and Educational Change. Harlow: Pearson Education.

Nowaczyk, R. H. (1982). "Sex-related differences in the colour lexicon”, in Language and Speech, 25: 257-265.

Ojeda Alba, J. and Jiménez Catalán, R. M. (2007). "The worlds children's words build”, in Didáctica, 19: 155-172.

Pavlenko, Aneta. (2005). Emotions and Multilingualism. Cambridge: Cambridge University Press.

Rich, E. (1977). "Sex-related differences in colour vocabulary", in Language and Speech, 20: 404409.

Richards, J. C. (1976). "The role of vocabulary", in TESOL Quarterly, 10, 1: 77-89.

Rosch, E. (1975). "The nature of mental codes for color categories", in Journal of Experimental Psychology: Human Perception and Performance, 1: 303-322.

Santrock, J.W. (2001). Child Development. New York: McGraw Hill.

Schmitt, N. and McCarthy, M. (eds.)(1997). Vocabulary: Description, Acquisition and Pedagogy. Cambridge: Cambridge University Press.

Singleton, D. (1999). Exploring the Second Language Mental Lexicon. Cambridge: Cambridge University Press.

Smith, M. K. (1990). "Image and identity: clothing and adolescence in the 1990's. from http:// eric.ed.gov/ERICDocs/data/ericdocs2sq1/content_storage_01/0000019b/80/14/2f/07.pdf, ERIC ERD, accessed 25 November, 2008.

Solomon, M. R. (1996). Consumer Behaviour, $3^{\text {rd }}$. edition. New Jersey: Prentice Hall.

Stemtröm, A.N., Andersen, G. and Hasund, I.K. (2002). Trends in Teenage Talk: Corpus Compilation, Analysis and Findings. Amsterdam \& Philadelphia: John Benjamins.

Sunderland, J. (2000). "Issues of language and gender in second and foreign language education", in Language Teaching 33/4: 203-223.

Swaringen, S., Layman, S. and Wilson, A. (1978). "Sex differences in colour naming”, in Perceptual and Motor Skills, 47: 440-442.

Tannen, D. (1990). You Just don't Understand: Women and Men in Conversation. New York: Ballantine Books.

Thomas, L.L., Curtis, A.J., and Bolton, R. (1978). "Sex differences in elicited color lexicon size", in Perceptual and Motor Skills 47: 77-8.

Tondl, R.M. (1994). "Using clothing choices and body image to enhance self-esteem", in Journal of Extension, 32: 2.

Waitley, D. (2006). Wordmaster: Improve your Word Power. (Compact Disc) New York: Hachette Audio.

Weatherall, A. (2002). Gender, Language, and Discourse. London: Routledge.

Wilkins, D. (1972). Linguistics in Language Teaching. London: Edward Arnold.

Yang, Yonglin. (2001). "Sex and Language proficiency level in colour-naming performance: an ESL/ EFL perspective", in International Journal of Applied Linguistics, vol. 11, 2: 238.

http://www.executivevocabulary.com/, accessed 15 July, 2008.

http://www.bestshareware.net/download/ultimate-vocabulary-success, accessed 21 July, 2008.

http://teens.lovetoknow.com/Flirting_Tips_for_Teenagers, accessed 7th November, 2008. 